\title{
SUPPORT OF SCHEDULING OF MULTIPRODUCT PIPELINE SYSTEMS USING SIMULATION IN WITNESS
}

\author{
Strachotova, D. ${ }^{*} \#$ \& Dyntar, J. ${ }^{* *}$ \\ ${ }^{*}$ University of Chemistry and Technology Prague, School of Business, Technicka 5, 16628 Praha 6, \\ Czech Republic \\ ** Technical University of Liberec, Faculty of Economics, Voronezska 13, 46001 Liberec 1, \\ Czech Republic \\ E-Mail: dana.strachotova@vscht.cz, jakub.dyntar@tul.cz ( ${ }^{\#}$ Corresponding author)
}

\begin{abstract}
In this paper, we describe the efficient discrete modelling of multiproduct pipeline systems in Witness simulation software environment. Our simulation model consists of 6 blocks called System structure, Pumping modes, Pumping schedule, Pumping execution, Collecting of outputs and Simulation run control and is supported by MS Excel. Algorithm for the assignment of a scheduled pumping requirement to execution is proposed too. Our model is innovative in that pipelines for the transport of products, tanks for storing products in warehouses as well as the products themselves and their material flow are represented neither by the continuous physical elements (Pipes, Tanks, Fluids) nor their discrete equivalent (Conveyors, Buffers, Parts) but by the logical elements called Variables. Avoiding physical elements enables efficient modelling of bidirectional flow of products in a pipeline and furthermore leads to the high speed of a simulation run. Based on the outputs of simulation of a simple pipeline system we show how our model can be used to support scheduling in complex multiple sources, multiple destinations pipeline networks.

(Received in May 2021, accepted in July 2021. This paper was with the authors 2 weeks for 1 revision.)
\end{abstract}

Key Words: Logistics, Scheduling, Pipeline System, Discrete-Event Simulation, Witness

\section{INTRODUCTION}

The transportation via pipelines represents the most reliable and cost-effective option for huge amounts of liquid and gaseous materials [1]. For the past five decades, pipelines have primarily been used by the oil industry to transport crude oil and its derivatives. Pipeline systems are typically multiproduct, meaning they transport multiple types of products through the same line. The goal of scheduling transport operations in a pipeline system is to meet the local demand of each linked node, ensuring proper stock control while adhering to many operational limitations such as flow rate constraints. [2]. Pipeline short-term scheduling is a difficult problem, for which a number of mixed-integer (non)linear programming (MI(N)LP) formulations have been developed and described in the scientific literature [3]. Discrete-time representation that divides the scheduling horizon into uniform time intervals of fixed duration $[4,5]$ is currently replaced with continuous-time or hybrid-time representation leading to the reduction of scale of the mathematical model [6-8]. Despite that MI(N)LP scheduling tasks remain NP-hard or worse which means that they could not be solved in polynomial time [9]. Moreover, although scientific literature contains many studies dealing with scheduling of pipeline networks most of them focus just on a unidirectional flow of products.

An alternative to the application of mathematical programming methods in the pipeline scheduling represent for example heuristic modules [10], constraint programming [11] and also discrete-event simulation [12]. These approaches are suitable mainly in the scheduling of pipeline networks with more complex structures [13]. Discrete-event simulation is a method of modelling a system as a discrete sequence of events using a computer [14]. Simulation has a number of advantages over other operational research methodologies, including the ability to 
experiment with any aspect of a business system [15]. It also enables to speed up time to study a system over a long period of time or to slow down to study its behaviour more closely [16].

Witness is a commercial simulation tool developed by Lanner Group Ltd. [17] with many applications in decision-making in production and logistics that are described in the literature [18-20]. It contains pre-defined physical elements suitable for modelling various both discrete and continuous logistics systems. On the other, based on our experience, when dealing with complex pipeline networks the application of physical elements suffers from several drawbacks. Continuous elements such as Tanks, Pipes and Fluids are designed to simulate only a system with unidirectional flow of products. Similarly when continuous elements are replaced with their discrete equivalent (i.e. Buffers and Conveyors) and Fluids are discretized with help of Parts it is possible to simulate bidirectional flow of product but a large number of physical elements in the model slows its run significantly. This is crucial when a simulation is designed to support a short-term scheduling.

The goal of this paper is to propose and describe the efficient way of modelling complex multiproduct pipeline systems in Witness simulation software environment. Our model is innovative in that pipelines for the transport of products, tanks for storing products in warehouses as well as the products themselves and their material flow are represented neither by the continuous physical elements (Pipes, Tanks, Fluids) nor their discrete equivalent (Conveyors, Buffers, Parts) but by the logical elements called Variables. Furthermore, we propose an effective algorithm for the assignment of a scheduled pumping requirement to execution. Based on the outputs of a simple pipeline system simulation we show how our model can be used to support scheduling in multiple-sources, multiple-destinations pipeline networks with bidirectional flow of products.

\section{SIMULATION OF A PIPELINE SYSTEM IN WITNESS}

\subsection{Model description}

Basic elements in our simulation model of a pipeline system are called demand point, entry point, warehouse, pipe and product. A demand point requires certain amount of a product in a certain period of time in a warehouse. Opposite to a demand point is an entry point that is responsible for deliveries of products to warehouses. Warehouses are equipped with storage tanks, one tank for one product. A pipe connects two warehouses and at any time of simulation it is filled with products. The rules that are addressed during the transportation of products through a pipeline system include [21]:

- a pipe fills and empties one tank at a time,

- tanks being filled cannot be emptied,

- an entry point can feed only one tank at a time and

- a demand point can only be fed by one tank at a time.

Our simulation model of a pipeline system in Witness environment consists of 6 blocks (see Fig. 1). The first block is called System structure and consists solely of Variables. These Variables contain information about the number of warehouses, demand points, entry points, pipes and products. For each warehouse, characteristics such as number of tanks and their storage capacity, initial stock level and a product are imported to simulation via Initialize Actions of the model from MS Excel using XLReadArray command. Each tank in a warehouse is also controlled by binary Variable deciding whether the tank is available for receiving or dispatch of a product (i.e. $0=$ available, $1=$ unavailable). In case of pipes, information about initial batch sizes of products and their arrangement in a pipe is necessary.

The second block contains Variables describing pumping modes, their relationships and availability during the simulation run. Each pumping mode is a sequence of integer numbers 
representing a specific interconnection between two warehouses through a pipe or between a warehouse and a demand or entry point. As in case of the tanks in warehouses, the availability of pumping modes is controlled by binary Variable. A pumping mode becomes unavailable to avoid situations that different pumping modes use the same pipe, more tanks in a warehouse feed a demand point with products or more tanks in a warehouse receive products from an entry point simultaneously. Description of pumping modes and their relationships are imported to simulation via Initialize Actions of the model from MS Excel using XLReadArray command.

The block called Pumping schedule represent Variables that comprise information about required start of pumping of a certain quantity of a product according to a pumping mode and performance. Again, this information is imported to simulation via Initialize Actions of the model from MS Excel using XLReadArray command.

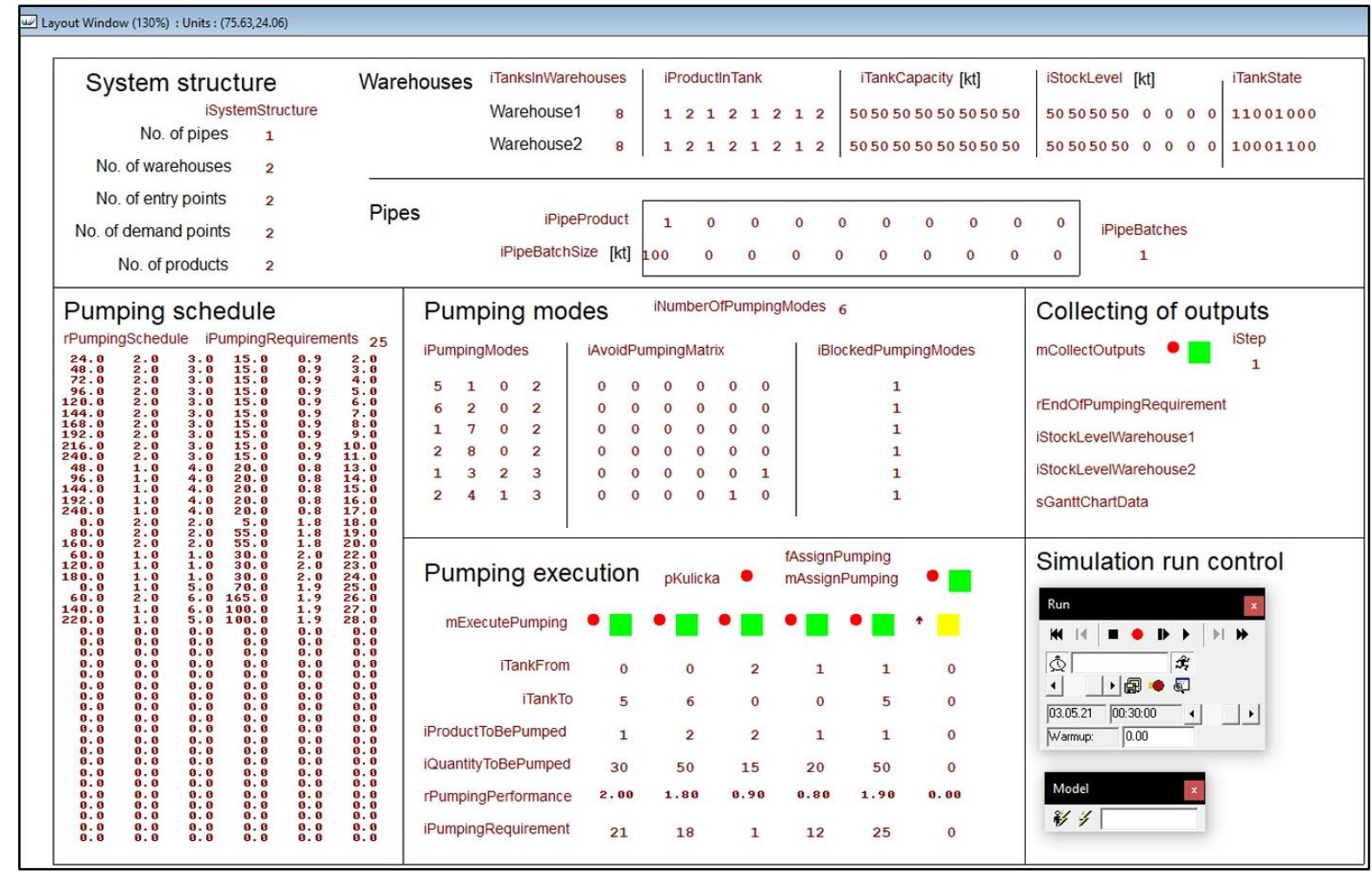

Figure 1: Simulation model of a pipeline system in Witness environment.

Pumping execution block consists of two Machines that are responsible for assignment and execution of pumping. First Machine repeatedly in a relatively short time (e.g. 1 time unit) pulls Part from World attempting (in Actions on Input) to assign a pumping through the algorithm forming the body of Void Function. The algorithm is shown in Fig. 2. In case that a pumping is assigned (i.e. variables in the Pumping execution block are set $>0$ ), second machine that is the part of the Pumping execution block pulls repeatedly Part out of World. Each single Part represents a certain amount of product (e.g. $1 \mathrm{t}, 100$ pcs...) and Cycle Time of Machine is therefore based on pumping performance. When the Cycle Time is over Actions on Finish take place including stock level updates in tanks and pipes and also assigned quantity to be pumped is decreased. If assigned quantity to be pumped is equal to zero appropriate pumping modes and tanks are set to be available for another assignment, simulation time of the pumping requirement finish is recorded, the rest of Variables involved in the Pumping execution block are set equal to zero and Void Function with the algorithm for the assignment of a pumping is called. During the simulation information about pumping mode that controls every pumping execution is represented by the quantity of Machine. This quantity is in Initialize Actions of the model set equal to number of pumping modes with help of SET QUANTITY OF command. 
Next block called Collecting of outputs consists of one Machine and a set of variables according to what outputs are the subject of interest. Except the Variable for recording simulation time of the pumping requirement finish during the pumping execution (see description above) other useful outputs are for example stock levels in warehouses, utilization of tanks and pipes by on shift time or Gantt charts. The collection of outputs itself is carried out through Actions on Input in the Machine pulling and pushing Part repeatedly in a relatively short time (e.g. 1 time unit). When the planned simulation time is reached, the simulation outputs are exported to MS Excel via User Actions using XLWriteArray command.

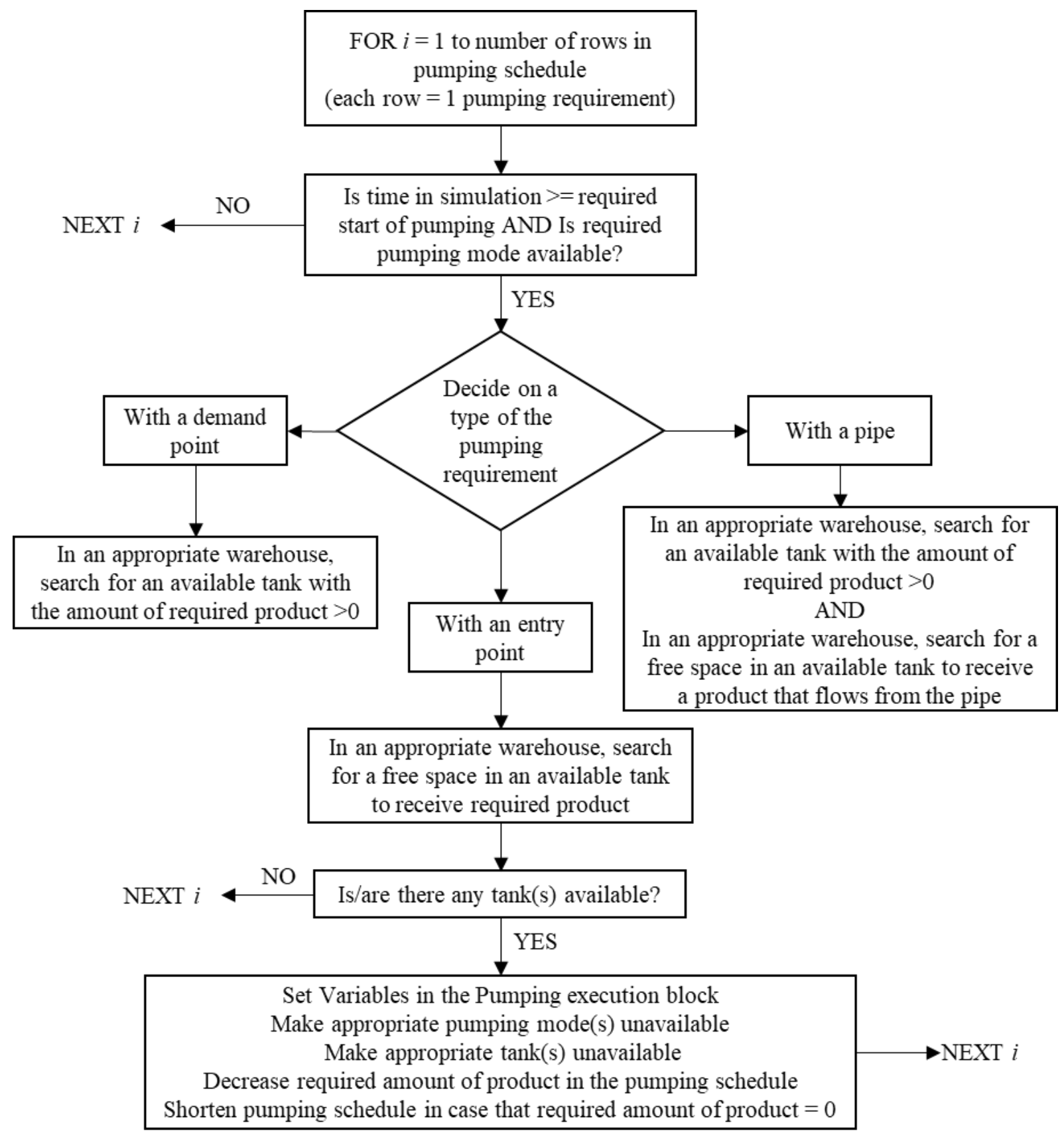

Figure 2: Algorithm for the assignment of a pumping.

And finally the block called Simulation run control contains Witness toolbars Run and Model and is suitable to run the simulation in different pace (Step, Run, Batch), with/without graphic (Step, Run/Batch) and to call User Actions ensuring the export of simulation outputs. 


\subsection{Simulation of a simple pipeline system}

The model described in previous chapter is applied to verify the feasibility of a pumping schedule in a simple pipeline system. The system consists of 2 warehouses connected through 1 pipe, 1 entry point feeding warehouse 1 with product 1,1 entry point feeding warehouse 2 with product 2, 1 demand point demanding product 2 in warehouse 1 and 1 demand point demanding product 1 in warehouse 2 . Each warehouse is equipped with 8 tanks, each with the capacity $50 \mathrm{kt}, 4$ tanks in a warehouse to store product 1 and 4 tanks for product 2 . Initial stock in each warehouse represents 2 full tanks with product 1 and 2 full tanks with product 2 . The pipe holds the maximum of $100 \mathrm{kt}$ of products with initial state represented by 1 batch of product 1 . In the simulation 6 pumping modes are available (see Table I).

Table I: Pumping modes.

\begin{tabular}{|c|c|c|c|c|}
\hline Pumping mode & Element 1 & Element 2 & Element 3 & No. of elements in pumping mode \\
\hline 1 & 5 & 1 & & 2 \\
\hline 2 & 6 & 2 & & 2 \\
\hline 3 & 1 & 7 & & 2 \\
\hline 4 & 2 & 8 & & 2 \\
\hline 5 & 1 & 3 & 2 & 3 \\
\hline 6 & 2 & 4 & 1 & 3 \\
\hline
\end{tabular}

Coding of elements in pumping modes available in the simulation is described in Table II.

Table II: Coding of elements in pumping modes.

\begin{tabular}{|l|l|}
\hline \multicolumn{1}{|c|}{ Element } & Coded as \\
\hline Warehouses & from 1 to 2 \\
\hline Pipes & 3 is pipe 1 direction $1 ; 4$ is pipe 1 direction 2 \\
\hline Entry points & from 5 to 6 \\
\hline Demand points & from 7 to 8 \\
\hline
\end{tabular}

Pumping schedule to be verified via the simulation is shown in Table III.

Table III: Pumping schedule (optimized length).

\begin{tabular}{|c|c|c|c|c|}
\hline Start of pumping $[\mathrm{h}]$ & Product & Pumping mode & Quantity $[\mathrm{kt}]$ & Pumping performance $[\mathrm{kt} / \mathrm{h}]$ \\
\hline $0-240$ step 24 & 2 & 3 & 15 & 0.9 \\
\hline $0-240$ step 48 & 1 & 4 & 20 & 0.8 \\
\hline $0-160$ step 80 & 2 & 2 & 55 & 1.8 \\
\hline $0-180$ step 60 & 1 & 1 & 30 & 2 \\
\hline 0 & 1 & 5 & 120 & 1.9 \\
\hline 60 & 2 & 6 & 165 & 1.9 \\
\hline 140 & 1 & 6 & 100 & 1.9 \\
\hline 220 & 1 & 5 & 100 & 1.9 \\
\hline
\end{tabular}

Pumping schedule covers time period of the length of 11 days. The operation of the system is continuous. The Cycle Time of the Machine responsible for assignment of a pumping is $1 \mathrm{~h}$ as well as the Cycle Time of the Machine responsible for the collecting of outputs. The Part passing through the Machine responsible for the pumping execution represents $1 \mathrm{kt}$ of a product. 
To carry out simulations computer with the processor Intel Core i7 - 2.8 GHz, 16 GB RAM is used.

\subsection{Simulation results}

Simulation time necessary to complete all pumping requirements from the pumping schedule is $275 \mathrm{~h}$. Based on recorded simulation time of the pumping requirement finish the delay for $i^{\text {th }}$ pumping requirement from the schedule is calculated using Eq. (1):

$$
\text { Delay }_{i}=\text { Recorded simulation time of finish } \text { Projected time of finish }_{i}
$$

where projected time of finish for $i^{\text {th }}$ pumping requirement from the schedule is calculated using Eq. (2):

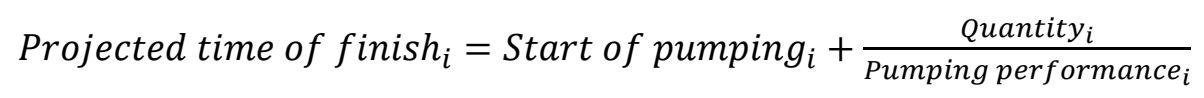

Delays for pumping requirements are grouped according to the type and maximum is found (see Table IV).

Table IV: Delay in pumping requirements finish.

\begin{tabular}{|l|c|c|}
\hline Type of pumping requirement & Delayed pumping requirements & Max. delay $[\mathrm{h}]$ \\
\hline With a demand point & 0 & 0 \\
\hline With an entry point & 0 & 0 \\
\hline With a pipe & 3 & 30 \\
\hline
\end{tabular}

Results in Table IV show that 3 pumping requirements with a pipe (i.e. product movements within the system) need to be re-scheduled. It is either because of insufficient pumping performance that for example in case of requirement 25 causes its finish at simulation time 63 when subsequent requirement is scheduled to start at simulation time 60 or because of the necessity to interrupt pumping (requirement 27) in case that required product is available just in $1 \operatorname{tank}(\operatorname{tank} 7)$ and this tank is used to feed a demand point (requirement 16) at the same time (see Table V with Gantt chart).

Table V: Gantt chart - simulation time 195-218 h (Part 1).

\begin{tabular}{|c|c|c|c|c|c|c|c|c|c|}
\hline Time[h] / Pumping requirement & 8 & 9 & 10 & 15 & 16 & 17 & 26 & 27 & 28 \\
\hline 195 & & from 2 & & & from 7 & & & 5 to 6 & \\
\hline 196 & & from 2 & & & from 7 & & & 5 to 6 & \\
\hline 197 & from 2 & & & from 7 & & & 5 to 6 & \\
\hline 198 & from 2 & & from 7 & & & & \\
\hline 199 & from 2 & & from 7 & & & & \\
\hline 200 & from 2 & & from 7 & & & & \\
\hline 201 & from 2 & & from 7 & & & & \\
\hline 202 & from 2 & & from 7 & & & & \\
\hline 203 & from 2 & & from 7 & & & & \\
\hline 204 & from 2 & & from 7 & & & & \\
\hline 205 & from 2 & & from 7 & & & & \\
\hline 206 & from 2 & & from 7 & & & & \\
\hline 207 & from 2 & & from 7 & & & & \\
\hline 208 & from 2 & & from 7 & & & & \\
\hline 209 & & & & & from 7 & & & & \\
\hline
\end{tabular}


Table V: Gantt chart - simulation time 195-218 h (Part 2).

\begin{tabular}{|c|l|c|c|c|c|c|c|c|c|}
\hline Time[h] / Pumping requirement & 8 & 9 & 10 & 15 & 16 & 17 & 26 & 27 & 28 \\
\hline 210 & & & & & from 7 & & & & \\
\hline 211 & & & & & from 7 & & & & \\
\hline 212 & & & & & from 7 & & & & \\
\hline 213 & & & & & from 7 & & & & \\
\hline 214 & & & & & from 7 & & & & \\
\hline 215 & & & & & from 7 & & & & \\
\hline 216 & & & from 2 & & from 7 & & & & \\
\hline 217 & & & from 2 & & & & & 7 to 4 & \\
\hline 218 & & & from 2 & & & & & 7 to 4 & \\
\hline
\end{tabular}

Inventory in warehouses during simulation time is shown in Figs. 3 and 4. In warehouse 1, minimal stock level for product 1 reaches $17 \mathrm{kt}$ at simulation time 60 while minimal stock level for product 2 reaches $25 \mathrm{kt}$ at simulation time 113. Storage capacity in warehouse 1 is completely filled just in case of product 1 during time period 195-222. In warehouse 2, minimal stock level for product 1 reaches $21 \mathrm{kt}$ at simulation time 222 while minimal stock level for product 2 reaches $45 \mathrm{kt}$ at simulation time 150 .

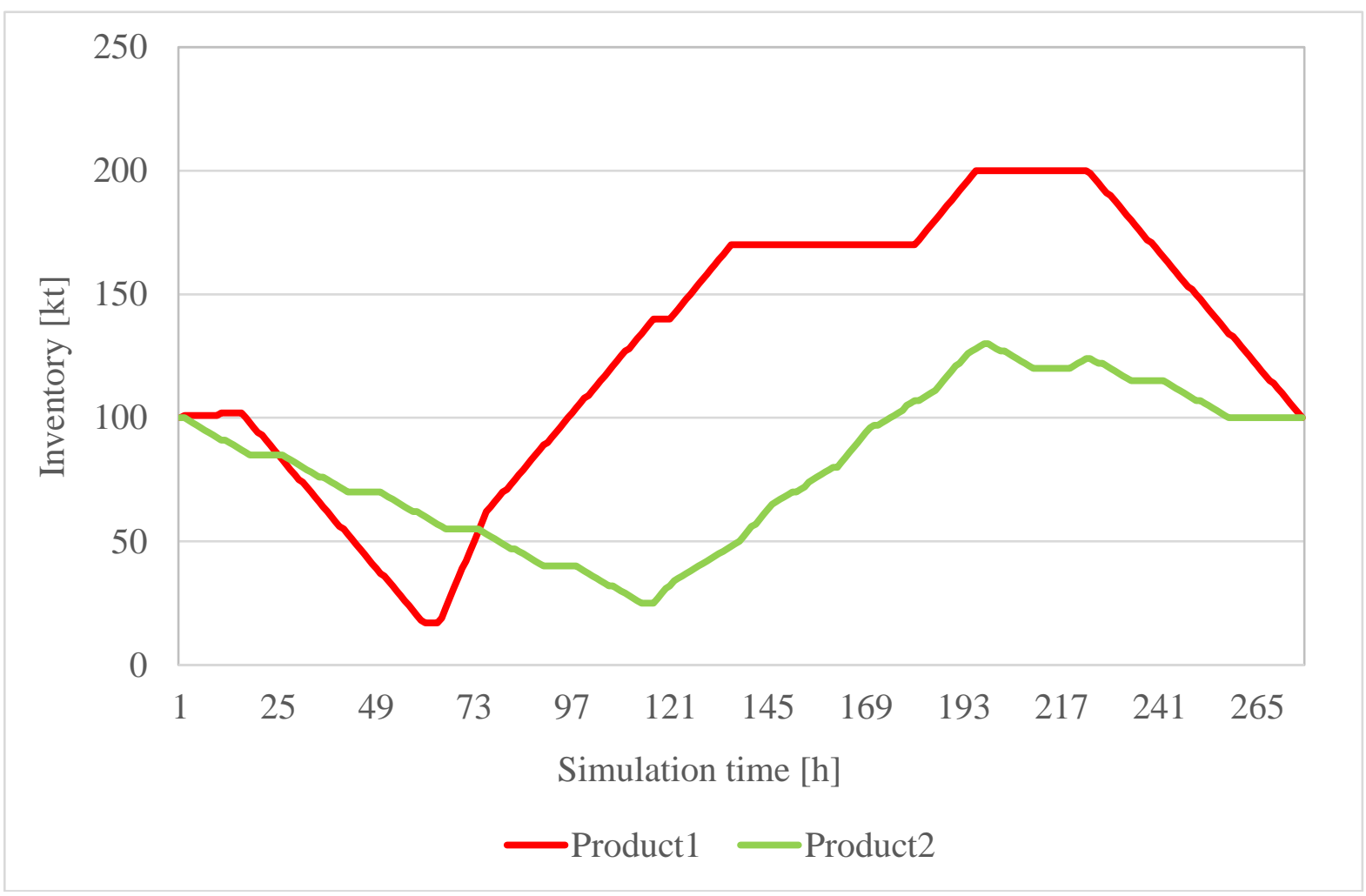

Figure 3: Inventory - warehouse 1. 


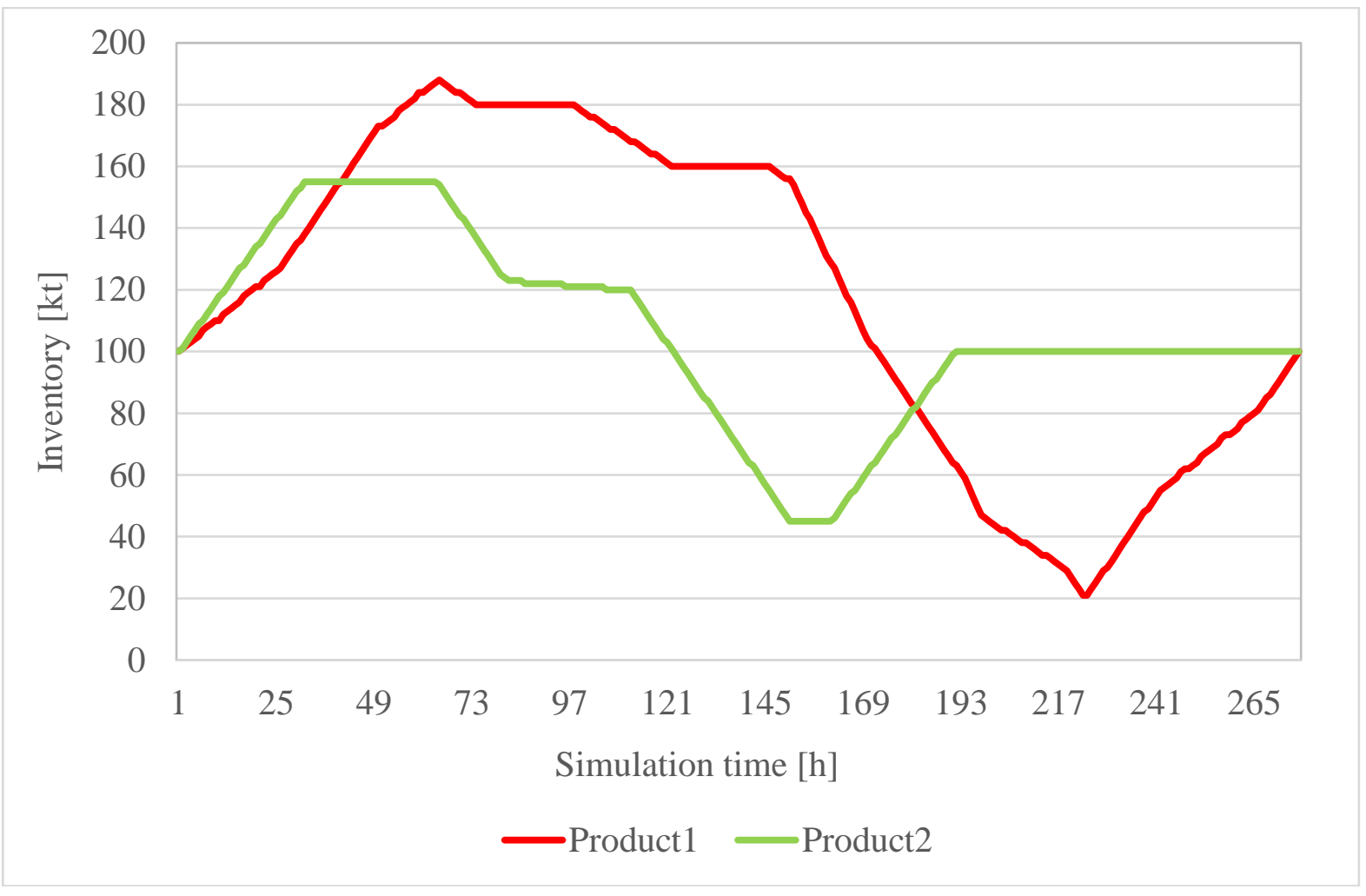

Figure 4: Inventory - warehouse 2.

Utilization of the pipe by on shift time is almost $93 \%$.

\section{CONCLUSION}

The Witness simulation software environment and the chosen modelling technique bring a number of advantages from the scheduling point of view. Discrete-time model has the ability to handle a wide range of processing features and enables modelling of time-varying resource availability. Increasing the quantity of elements that are part of blocks called System structure, Pumping modes and Pumping execution enables to model a large number of different variants of a system. This can be used to set or verify schedules throughout the complex multiplesources, multiple-destinations pipeline networks [22]. Furthermore, in our model pipes are represented with Variables enabling efficient modelling of bidirectional flow of products that increases the utilization of pipeline transportation capacity. Scheduling of pipelines with bidirectional flow of products is the phenomenon which is described in the scientific literature insufficiently. The relatively low number of physical elements used in our model has a positive effect on the speed of its running. Moreover, the computational time of the model can be determined by selecting the degree of discretization of the material flow affecting number of cycles occurring in Machines that are responsible for the pumping execution. This is useful in situations when a system needs to be explored in full detail including graphic (i.e. Step and Run mode in Witness environment) or in situations when calculations are required promptly (i.e. Batch mode in Witness environment). The discretization of the material flow and possible set up of its level is also useful in situations when the occurrence of blended zones of products in pipes influence the feasibility of a pumping schedule [23, 24]. Extending the block called System structure to Variables with information about the characteristics of the pumped products (e.g. the content of sulphur in a crude oil) is appropriate in a system in which mixing of products is required [25, 26]. By limiting the availability of pumping modes and tanks in warehouses, it is also possible to simulate maintenance or failures $[27,28]$. Thanks to the simplicity and the 
use of a limited number of basic discrete elements, the model can be easily transferred to the environment of other simulation products, such as Simul8 or Arena [29, 30].

As it stands right now our model can provide a planner with support when compiling a pipeline schedule. This leads to time savings because of avoiding manual calculations usually executed in spreadsheets. Despite the proposed model offers flexibility in terms of both computational enhancements and modelling extensions one has to keep in mind that it is not able to generate a schedule itself. That is why hybrid simulation-optimization approach seems to be more appropriate way of addressing industrial-scale problems [31,32]. Scheduling optimization models are created on a semi-abstract level, ignoring potentially crucial nonlinear and stochastic features. This is required because otherwise, the resultant sophisticated optimization models will be impossible to solve and thus useless. On the other hand simulation models are created to simulate a real system and include the necessary stochastic and nonlinear features. These simulation models are used as test beds for analysing and improving real-world situations through trial and error.

In our future work we will focus on combining our simulation model with optimization models based on mathematical programming (both discrete-, continuous-time representations) to obtain feasible and optimal or nearly optimal schedule in a whole supply chain. Our subject of interest is the supply chain of crude oil transportation ( 2 oil pipelines, 2 warehouses with charging tanks), crude oil processing (3 refineries) and the distribution of fuels (pipeline network, 17 distribution centres) covering the demand for petrol and diesel in the Czech Republic.

\section{REFERENCES}

[1] MirHassani, S. A.; Ghorbanalizadeh, M. (2008). The multi-product pipeline scheduling system, Computers \& Mathematics with Applications, Vol. 56, No. 4, 891-897, doi:10.1016/ j.camwa.2008.01.035

[2] Meira, W. H. T.; Magatao, L.; Neves, F.; Arruda, L. V. R.; Vaqueiro, J. P.; Relvas, S.; BarbosaPovoa, A. P. (2021). A solution framework for the long-term scheduling and inventory management of straight pipeline systems with multiple-sources, Computers \& Operations Research, Vol. 127, Paper 105143, 25 pages, doi:10.1016/j.cor.2020.105143

[3] Mostafaei, H.; Castro, P. M.; Oliveira, F.; Harjunkoski, I. (2021). Efficient formulation for transportation scheduling of single refinery multiproduct pipelines, European Journal of Operational Research, Vol. 293, No. 2, 731-747, doi:10.1016/j.ejor.2020.12.034

[4] Shah, N. (1996). Mathematical programming techniques for crude oil scheduling, Computers \& Chemical Engineering, Vol. 20, No. 2, 1227-1232, doi:10.1016/0098-1354(96)00212-8

[5] Rejowski, R.; Pinto, J. M. (2004). Efficient MILP formulations and valid cuts for multiproduct pipeline scheduling, Computers \& Chemical Engineering, Vol. 28, No. 8, 1511-1528, doi:10.1016/j.compchemeng.2003.12.001

[6] Neves, F.; Magatão, L.; Stebel, S. L.; Boschetto, S. N.; Felizari, L. C.; Czaikowski, D. I.; Rocha, R.; Ribas, P. C. (2007). An efficient approach to the operational scheduling of a real-world pipeline network, Computer Aided Chemical Engineering, Vol. 24, 697-702, doi:10.1016/S15707946(07)80139-8

[7] Rejowski, R.; Pinto, J. M. (2008). A novel continuous time representation for the scheduling of pipeline systems with pumping yield rate constraints, Computers \& Chemical Engineering, Vol. 32, No. 4-5, 1042-1066, doi:10.1016/j.compchemeng.2007.06.021

[8] Zhang, H.; Liang, Y.; Liao, Q.; Wu, M.; Yan, X. (2017). A hybrid computational approach for detailed scheduling of products in a pipeline with multiple pump stations, Energy, Vol. 119, 612628, doi:10.1016/j.energy.2016.11.027

[9] Mor, B.; Shabtay, D.; Yedidsion, L. (2021). Heuristic algorithms for solving a set of NP-hard single-machine scheduling problems with resource-dependent processing times, Computers \& Industrial Engineering, Vol. 153, Paper 107024, 17 pages, doi:10.1016/j.cie.2020.107024 
[10] Sasikumar, M.; Prakash, P. R.; Patil, S. M.; Ramani, S. (1997). PIPES: A heuristic search model for pipeline schedule generation, Knowledge-Based Systems, Vol. 10, No. 3, 169-175, doi:10.1016/S0950-7051(97)00026-9

[11] Moura, A. V.; de Souza, C. C.; Cire, A. A.; Lopes, T. M. (2008). Planning and scheduling the operation of a very large oil pipeline network, Stuckey, P. J. (Ed.), Principles and Practice of Constraint Programming, Springer, Berlin, 36-51, doi:10.1007/978-3-540-85958-1_3

[12] García-Sánchez, Á.; Arreche, L. M.; Ortega-Mier, M. (2008). Combining simulation and tabu search for oil-derivatives pipeline scheduling, Xhafa, F.; Abraham, A. (Eds.) Metaheuristics for Scheduling in Industrial and Manufacturing Applications, Springer, Berlin, 301-325, doi:10.1007/978-3-540-78985-7_12

[13] Xu, N.; Liao, Q.; Li, Z.; Liang, Y.; Qiu, R.; Zhang, H. (2021). An efficient decomposition approach for the low-energy scheduling of a straight multiproduct pipeline, Chemical Engineering Research and Design, Vol. 165, 341-360, doi:10.1016/j.cherd.2020.10.022

[14] Agalianos, K.; Ponis, S. T.; Aretoulaki, E.; Plakas, G.; Efthymiou, O. (2020). Discrete event simulation and digital twins: review and challenges for logistics, Procedia Manufacturing, Vol. 51, 1636-1641, doi:10.1016/j.promfg.2020.10.228

[15] Ponis, S. T.; Delis, A.; Gayialis, S. P.; Kasimatis, P.; Tan, J. (2013). Applying discrete event simulation (DES) in healthcare: the case for outpatient facility capacity planning, International Journal of Healthcare Information Systems and Informatics, Vol. 8, No. 3, 58-79, doi:10.4018/jhisi.2013070104

[16] Dyntar, J.; Lachman, J.; Mencikova, A.; Botek, M. (2021). Application of dynamic simulation in planning and scheduling in oil chemistry, Chemicke Listy, Vol. 115, No. 4, 188-194

[17] Lanner Group Limited. Witness Horizon, from https://www.lanner.com/en-us/technology/witnesssimulation-software.html, accessed on 11-05-2021

[18] Fedorko, G.; Molnar, V.; Honus, S.; Neradilova, H.; Kampf, R. (2018). The application of simulation model of a milk run to identify the occurrence of failures, International Journal of Simulation Modelling, Vol. 17, No. 3, 444-457, doi:10.2507/IJSIMM17(3)440

[19] Tvrdon, L.; Fedorko, G. (2020). Usage of dynamic simulation in pressing shop production system design, International Journal of Simulation Modelling, Vol. 19, No. 2, 185-196, doi:10.2507/IJSIMM19-2-494

[20] Wang, Q.-Z.; Chen, J.-M.; Tseng, M.-L.; Luan, H.-M.; Ali, M. H. (2020). Modelling green multimodal transport route performance with witness simulation software, Journal of Cleaner Production, Vol. 248, Paper 119245, 12 pages, doi:10.1016/j.jclepro.2019.119245

[21] Lee, H.; Pinto, J. M.; Grossmann, I. E.; Park, S. (1996). Mixed-integer linear programming model for refinery short-term scheduling of crude oil unloading with inventory management, Industrial \& Engineering Chemistry Research, Vol. 35, No. 5, 1630-1641, doi:10.1021/ie950519h

[22] Oliveira, F.; Nunes, P. M.; Blajberg, R.; Hamacher, S. (2016). A framework for crude oil scheduling in an integrated terminal-refinery system under supply uncertainty, European Journal of Operational Research, Vol. 252, No. 2, 635-645, doi:10.1016/j.ejor.2016.01.034

[23] Ekambara, K.; Joshi, J. B. (2003). Axial mixing in pipe flows: turbulent and transition regions, Chemical Engineering Science, Vol. 58, No. 12, 2715-2724, doi:10.1016/S0009-2509(03)00102-7

[24] Sepehr, H.; Nikrityuk, P.; Breakey, D.; Sanders, R. S. (2019). Numerical study of crude oil batch mixing in a long channel, Petroleum Science, Vol. 16, No. 1, 187-198, doi:10.1007/s12182-0180276-4

[25] Bai, L.; Jiang, Y.; Huang, D.; Liu, X. (2010). A novel scheduling strategy for crude oil blending, Chinese Journal of Chemical Engineering, Vol. 18, No. 5, 777-786, doi:10.1016/S10049541(09)60129-4

[26] Li, J.; Karimi, I. A.; Srinivasan, R. (2009). Multi-period continuous-time formulation for integrated scheduling, blending, and distribution of refinery products, Computer Aided Chemical Engineering, Vol. 27, 1563-1568, doi:10.1016/S1570-7946(09)70651-0

[27] Zakikhani, K.; Nasiri, F.; Zayed, T. (2020). Availability-based reliability-centered maintenance planning for gas transmission pipelines, International Journal of Pressure Vessels and Piping, Vol. 183, Paper 104105, 9 pages, doi:10.1016/j.ijpvp.2020.104105 
[28] Senouci, A.; Elabbasy, M.; Elwakil, E.; Abdrabou, B.; Zayed, T. (2013). A model for predicting failure of oil pipelines, Structure and Infrastructure Engineering, Vol. 10, No. 3, 375-387, doi:10.1080/15732479.2012.756918

[29] SIMUL8 Corporation. SIMUL8 - Process Simulation Software, from https://www.simul8.com, accessed on 21-05-2021

[30] Rockwell Automation. Arena Simulation Software, from https://www.arenasimulation.com/, accessed on 22-05-2021

[31] Figueira, G.; Almada-Lobo, B. (2014). Hybrid simulation-optimization methods: A taxonomy and discussion, Simulation Modelling Practice and Theory, Vol. 46, 118-134, doi:10.1016/ j.simpat.2014.03.007

[32] Martins, S.; Amorim, P.; Figueira, G.; Almada-Lobo, B. (2017). An optimization-simulation approach to the network redesign problem of pharmaceutical wholesalers, Computers \& Industrial Engineering, Vol. 106, 315-328, doi:10.1016/j.cie.2017.01.026 